\title{
Copper Accumulates in Hemosiderins in Livers of Patients with Iron Overload Syndromes
}

\author{
Yukiya Ono ${ }^{1}$, Masatoshi Ishigami*1, Kazuhiko Hayashi ${ }^{1}$, Shinya Wakusawa ${ }^{2}$, Hisao Hayashi ${ }^{3}$, \\ Kotaro Kumagai ${ }^{4}$, Natsuko Morotomi ${ }^{5}$, Tetsuji Yamashita6 ${ }^{6}$, Miwa Kawanaka7, \\ Minemori Watanabe ${ }^{8}$, Hiroaki Ozawa ${ }^{9}$, Mayumi Tai ${ }^{10}$, Hiroaki Miyajima ${ }^{11}$, \\ Kentarou Yoshioka ${ }^{12}$, Yoshiki Hirooka ${ }^{1}$ and Hidemi Goto ${ }^{1}$
}

\begin{abstract}
${ }^{1}$ Department of Gastroenterology, Nagoya University Graduate School of Medicine, Nagoya, Japan; ${ }^{2}$ Department of Medical Laboratory Sciences, Nagoya University Graduate School of Medicine, Nagoya, Japan; ${ }^{3}$ Department of Medicine, Aichi Gakuin University School of Pharmacy, Nagoya, Japan; ${ }^{4}$ Digestive Disease and Lifestyle Related Disease, Kagoshima University Graduate School of Medical and Dental Sciences, Kagoshima, Japan; ${ }^{5}$ Department of Internal Medicine, Moji Hospital, Kitakyushu, Japan; ${ }^{6}$ Department of Medicine, Yoshida Hospital, Matsuyama, Japan; ${ }^{7}$ General Internal Medicine 2, Kawasaki Hospital, Kawasaki Medical School, Okayama, Japan; ${ }^{8}$ Department of Endocrinology and Diabetes, Okazaki City Hospital, Okazaki, Japan; ${ }^{9}$ Department of Pathology, Okazaki City Hospital, Okazaki, Japan; ${ }^{10}$ Department of Gastroenterology, Fukushima Rohsai Hospital, Fukushima, Japan; ${ }^{11}$ First Department of Medicine, Hamamatsu University School of Medicine, Hamamatsu, Japan; ${ }^{12}$ Department of Liver, Biliary Tract and Pancreas Diseases, Fujita Health University, Toyoake, Japan.
\end{abstract}

\begin{abstract}
In biology, redox reactions are essential and sometimes harmful, and therefore, iron metabolism is tightly regulated by cuproproteins. Since the state of copper in iron overload syndromes remains unclear, we investigated whether copper metabolism is altered in these syndromes. Eleven patients with iron overload syndromes participated in this study. The clinical diagnoses were aceruloplasminemia $(n=2)$, hemochromatosis $(n=5)$, ferroportin disease $(n=2)$, and receiving excess intravenous iron supplementation $(n=2)$. Liver specimens were analyzed using a light microscope and transmission electron microscope equipped with an X-ray analyzer. In addition to a large amount of iron associated with oxygen and phosphorus, the iron-rich hemosiderins of hepatocytes and Kupffer cells contained small amounts of copper and sulfur, regardless of disease etiology. Two-dimensional imaging clearly showed that cuproproteins were distributed homogenously with iron complexes within hemosiderins. Copper stasis was unlikely in noncirrhotic patients. The enhanced induction of cuproproteins by excess iron may contribute to copper accumulation in hemosiderins. In conclusion, we have demonstrated that copper accumulates in hemosiderins in
\end{abstract}

Keywords: Aceruloplasminemia; Cuproprotein induction; Ferroportin disease; Hemochromatosis; Hemosiderin; Iron copper interaction; Iron overload syndromes.

Abbreviations: aCP, aceruloplasminemia; $\mathrm{AGU}$, Aichi Gakuin University; $\mathrm{CP}$ ceruloplasmin; EDX, energy dispersive X-ray; FPN, ferroportin; $\mathrm{HH}$, hemochromatosis; HUH, Hamamatsu University Hospital; LC/ESI-MS/MS, liquid chromatography/electrospray ionization tandem mass spectrometric; MA, microanalysis; NUSM, Nagoya University School of Medicine; RE, reticuloendothelial cells; TEM, transmission electron microscopy.

Received: 08 February 2015; Revised: 24 March 2015; Accepted: 25 March 2015 DOI: $10.14218 / \mathrm{JCTH} .2015 .00004$.

*Correspondence to: Masatoshi Ishigami, Department of Gastroenterology and Hepatology, Nagoya University Graduate School of Medicine, 65 Tsurumai-cho, Showa-ku, Nagoya 466-8550, Japan. Tel: +81-52-744-2169, Fax: +81-52-7442178,E-mail: masaishi@med.nagoya-u.ac.jp iron overload conditions, perhaps due to alterations in copper metabolism.

(C) 2015 The Second Affiliated Hospital of Chongqing Medical University. Published by XIA \& HE Publishing Ltd. All rights reserved.

\section{Introduction}

The liver is critical for maintaining iron homeostasis, and hepatocytes are the main storage site of iron in the body. The peptide hepcidin, which is produced by hepatocytes, regulates the transport of iron into and around the body. In addition, hepatocytes synthesize transferrin and ceruloplasmin (CP), the main proteins involved in iron metabolism. Kupffer cells of the liver are the primary site of iron recycling for erythropoiesis as splenic macrophages. ${ }^{1,2}$ Since there is no secretory pathway for iron, a wide range of iron overload conditions have been identified. Hepcidin-dependent iron overload syndromes include aceruloplasminemia (aCP), hemochromatosis $(\mathrm{HH})$, and ferroportin (FPN). ${ }^{2,3}$ Iatrogenic iron disorders occur due to repeated blood transfusions and long-term excess iron supplementation. Regardless of the etiology, excess iron levels are initially stored in ferritin molecules and then in lysosomal hemosiderins as polymerized ferritin molecules. ${ }^{4}$

The liver also plays an important role in copper homeostasis. ${ }^{5}$ Copper is utilized by the liver to synthesize cuproproteins, including multicopper oxidases ${ }^{6}$ and $\mathrm{Cu} / \mathrm{Zn}$ superoxide dismutase. ${ }^{7}$ Excess levels of copper are physiologically secreted from the liver to the biliary system. Therefore, standard methods, either histochemistry or X-ray microanalysis (MA), cannot detect the small amounts of copper physiologically stored in hepatocyte lysosomes. However, in pathological conditions like chronic cholestasis and Wilson's disease, hepatic copper accumulates and may be detectable. Detoxified forms of excess copper have been visualized as thiol-rich cuproproteins in hepatocyte lysosomes. ${ }^{8}$ 
Since differences have been reported in the maintenance of iron and copper homeostasis in the body, ${ }^{2,5}$ it is possible that their storage and recycling systems may also differ in the liver. The lysosomal dense bodies of hepatocytes store iron and copper of various origins and release them when required through a specific acidification system. ${ }^{9,10}$ Some of the trace metals thus released may be utilized to renew transition element-containing molecules, while others may be delivered to extracellular pathways after reaching their destination in the transGolgi network. ${ }^{11}$ During these recycling processes of trace elements, excess copper may be secreted into the bile, whereas iron, which lacks a secretory pathway, may be restored in lysosomal dense bodies. Copper has been shown to disappear from the hepatocellular dense bodies of patients with Wilson's disease following long-term chelation therapy with penicillamine. ${ }^{5} \mathrm{~A}$ large amount of iron is removed from hemosiderin granules after repeated venesection, a standard regimen for hemochromatosis, due to enhanced erythropoiesis in the bone marrow. ${ }^{2}$ Therefore, in addition to storing the transition elements of iron and copper, lysosomal dense bodies may be central organelles for the homeostasis of trace elements. $^{12}$

Iron-induced oxidative stress impairs cell membranes and organelles through reactive oxygen species, ${ }^{13}$ and redox states are tightly regulated by cuproproteins in mitochondria and other reactive iron-containing organelles. ${ }^{14}$ To date, changes in the storage and recycling system of copper in the livers of patients with iron overload syndromes have not yet been examined in detail.

A microanalysis of transmission electron microscopy (TEM) equipped with an energy dispersive X-ray analyzer (EDX), which is more sensitive for visualizing iron and copper than light microscopic histochemistry, may provide more information on the storage and recycling of transition elements around lysosomal dense bodies. ${ }^{8,15}$ Using TEM-EDX MA, we determined whether $\mathrm{HH}$ and related iron overload conditions were widely associated with the altered metabolism of copper.

\section{Patients and methods}

\section{Patients with iron overload syndromes}

Eleven patients with iron overload syndromes, whose liver biopsy specimens were sequentially obtained between 1996 and 2014, were enrolled in this retrospective study. Their hepatocytes were all loaded with iron grains, as revealed histochemically by Berlin blue stain. Biochemical iron indices included the serum levels of ferritin and hepcidin 25 and iron saturation of transferrin, while copper parameters were serum levels of copper and CP. The new iron regulator hepacidin 25 was determined by a liquid chromatography/ electrospray ionization tandem mass spectrometric (LC/ ESI-MS/MS) method. ${ }^{16}$ Serum hepcidin 25 has been reported to be inadequately low in hemochromatosis and related disorders. $^{3}$

\section{Gene analysis}

Based on their clinical features, genetic backgrounds were investigated in all patients. They included HFE, TFR2, HAMP, $H J V, S L C 4 O A 1$, and $C P$ genes. Some patients underwent an additional analysis of the $A T P 7 B$ gene, which is responsible for Wilson's disease. These genes, except for $C P$, were analyzed at Aichi Gakuin University (AGU) and Nagoya University
School of Medicine (NUSM), while those for $C P$ were analyzed at Hamamatsu University Hospital (HUH). Informed consent was obtained from each patient prior to genetic testing according to the study protocols approved by the Ethics Committees of the participating institutes (AGU No. 6, 8, and 10, NUSM No. 277, and HUH No. 21-91).

DNA was extracted from peripheral blood cells. The coding regions and splicing sites of each gene were amplified by polymerase chain reaction, and its products were sequenced using a BigDye Terminator v3.1 Cycle Sequencing Kit and 3130 Genetic Analyzer (Applied Biosystems, Life Technology, Japan).

\section{Histochemical study of livers}

All liver specimens were obtained by fine needle or surgical wedge biopsy to evaluate diagnostic pathological changes, including iron and copper overload conditions. Liver specimens were fixed with $10 \%$ neutral formalin and embedded in paraffin blocks for standard histology. Berlin blue staining was used for iron, while rhodanic acid was used for copper.

\section{Electron microscopic study and X-ray microanalysis of livers}

Two pieces of $1 \mathrm{~mm}^{3}$ liver specimens were fixed with $2 \%$ glutaraldehyde in $0.1 \mathrm{M}$ phosphate buffer, followed by embedding in the epoxy resin TAAB812. In cases in which liver specimens had been stored in paraffin blocks, paraffin was extracted from the paraffin-embedded liver specimens by xylene solutions. Liver specimens were refixed with $2 \%$ glutaraldehyde and embedded in the epoxy resin. Ultrathin sections were mounted on gold grids. Sections stained with uranyl solution were examined under TEM (JEOL-1400, JEOL, Japan). Unstained sections were examined under TEM-EDX (JEM-2010 and JEM-2800, JOEL, Japan), as reported previously. ${ }^{15}$

Glutaraldehyde and epoxy resin embedding kits were purchased from TAAB Laboratories Equipment Ltd. (Berks, England), and gold grids were from Graticules Ltd. (Tonbridge, England). The pure water used in the present study was made by Elix Advantage 5 (Merck, Germany). Other chemicals and solutions, including phosphate buffer, were purchased from Nacalai Tesque Inc. (Kyoto, Japan).

An electron microscopic study with TEM was performed to visualize the intracellular distribution of dense bodies in hepatocytes and reticuloendothelial cells (RE), including Kupffer cells. Using the TEM-EDX of JEM-2010, MA on dense bodies in the hepatocytes were randomly performed by $X$-rays yielded from dense bodies that had been exposed to electron beams for a short period. Iron X-rays were always identified in the dense bodies studied. When copper $X$-rays were identified in a particular dense body, the total number of X-rays yielded from the dense body was counted for $200 \mathrm{~s}$ to complete an X-ray spectrum. More than 20 ironpositive dense bodies were analyzed per patient. A similar observational method was used for Kupffer cells in which a large number of iron-positive dense bodies had aggregated. The specific $\mathrm{K} \alpha \mathrm{X}$-rays of copper and iron were identified using an autoanalysis system equipped with EDX.

The accumulation of iron was classified into three stages and expressed as Fe $(+3)$ when the most dense bodies were heavily loaded with iron, as Fe (+2) when moderately loaded, and as Fe $(+1)$ when mildly loaded. Copper was expressed as $\mathrm{Cu}(+)$ when 
more than $10 \%$ of dense bodies were positive for a $\mathrm{Cu} \mathrm{K} \alpha$ peak, as $\mathrm{Cu}(+/-)$ when less than $10 \%$ of dense bodies were positive, and as $\mathrm{Cu}(-)$ when no $\mathrm{Cu} \mathrm{K} \alpha$ peak was observed. The twodimensional distribution of iron and other elements was mapped using scans of dense body-rich cytoplasm with the TEM-EDX of JEM-2800 for $480 \mathrm{~s}$. Au peaks were not examined in the present study because of an extrinsic element from gold grids.

\section{Results}

\section{Clinical features and diagnoses of patients}

The clinical features and diagnoses of patients are summarized in Table 1. The diagnosis/responsive gene name of iron overloading was aCP/CP in two patients, $\mathrm{HH} / \mathrm{HJV}$ in two, $\mathrm{HH} / T F R 2$ in three, and FPN/SLC4OA1 in one. One patient with clinical FPN and two with intravenous iron overload were free from any mutations associated with iron overload syndromes. No mutation was observed in ATP7B of the five patients studied. The pretreatment biochemical parameters of iron and copper metabolism and the morphological studies of the livers of patients are summarized in Table 2. The serum ferritin levels of all patients were higher than $900 \mathrm{ng} / \mathrm{mL}$. The iron saturation of transferrin was also high, except for in two patients with aCP. Serum hepcidin 25 levels were inadequately low in six patients with $\mathrm{HH}$ and $\mathrm{aCP}$. Circulating CP concentrations were high in five patients with $\mathrm{HH}, \mathrm{FPN}$, and intravenous iron overload.

\section{Histochemical study of livers}

One inclusion criterion for this study was the histochemical finding by Berlin blue staining of iron in most hepatocytes. Liver histology ranged from almost normal in a patient with intravenous iron supplementation and two patients with aCP to cirrhosis in three patients with $\mathrm{HH}$. Almost all grains in the hepatocytes and RE cells of all 11 patients were positive for iron. Iron deposits were selectively parenchymal in a patient with iron supplementation and two patients with aCP, parenchymal-dominant in five patients with $\mathrm{HH}$ (Fig. 1), and combined with parenchymal and RE cells in a patient with iron supplementation and two patients with FPN. The rhodanic acid stain for copper was difficult to evaluate because all grains were originally bronze in color due to the large amount of iron present (Fig. 2).

\section{Electron microscopic study and X-ray microanalysis of livers}

The ultrastructure of hepatocellular iron-rich dense bodies underTEM appeared to be similar among patients with different phenotypes. Dense bodies of various shapes and sizes aggregated in the Kupffer cells of three patients (Patients 8-10). Fig. 3 shows an X-ray spectrum obtained from a hepatocyte dense body complicated with cuproproteins. The specific Xray peaks of copper appeared in a limited number of dense bodies with high peaks for iron, which reflected copper colocalization with iron in iron-rich dense bodies.

Table 1. Patient characteristics

\begin{tabular}{|c|c|c|c|c|c|}
\hline Patient & Age/Sex & Main clinical features & $\begin{array}{l}\text { Organ damage other } \\
\text { than the liver due } \\
\text { to iron overloading }\end{array}$ & Genetic background & Diagnosis \\
\hline 1 & $44 / M$ & Insulin-dependent DM & $\begin{array}{l}\text { Central diabetes } \\
\text { insipidus, } \\
\text { hypothyroidism }\end{array}$ & $\begin{array}{l}1285-1286 \text { ins } 5 / 1285- \\
1286 \text { ins5 in } C P\end{array}$ & $\mathrm{aCP}$ \\
\hline 2 & $36 / M$ & Insulin-dependent DM & DM & $\begin{array}{l}2674 \mathrm{G}>\mathrm{A} / 2674 \mathrm{G}>\mathrm{A} \text { in } C P, \\
\text { no mutation in } A T P 7 B\end{array}$ & $\mathrm{aCP}$ \\
\hline 3 & $51 / F$ & Insulin-dependent DM & DM, pigmentation & $\begin{array}{l}934 \mathrm{C}>\mathrm{T} / 934 \mathrm{C}>\mathrm{T} \text { in } H J V \\
\text { no mutation in } A T P 7 B\end{array}$ & $\mathrm{HJV}-\mathrm{HH}$ \\
\hline 4 & $48 / M$ & Insulin-dependent DM & DM, pigmentation & $745 G>C / 745 G>C$ in $H J V$ & $\mathrm{HJV}-\mathrm{HH}$ \\
\hline 5 & $53 / F$ & $\begin{array}{l}\text { Biochemical liver } \\
\text { damage }\end{array}$ & None & $\begin{array}{l}\text { 1861-1872del12/1861- } \\
1872 \text { del12 in TRF2 }\end{array}$ & TFR2-HH \\
\hline 6 & $40 / M$ & Insulin-dependent DM & $\begin{array}{l}\text { DM, pigmentation, } \\
\text { hypogonadism }\end{array}$ & $\begin{array}{l}1100 T>G / 2008-2009 \text { delAC } \\
\text { in TRF2, No mutation in } A T P 7 B\end{array}$ & TFR2-HH \\
\hline 7 & $50 / M$ & $\begin{array}{l}\text { Biochemical liver } \\
\text { damage }\end{array}$ & None & $\begin{array}{l}1861-1872 \text { del } 12 / 1861- \\
1872 \text { del12 in TRF2, } \\
\text { no mutation in ATP7B }\end{array}$ & TFR2-HH \\
\hline 8 & $66 / M$ & Insulin-dependent DM & DM, pigmentation & $\begin{array}{l}470 A<C / \text { wt in } S \angle C 40 A 1 \text {, } \\
\text { no mutation in } A T P 7 B\end{array}$ & FPN \\
\hline 9 & $79 / F$ & $\begin{array}{l}\text { Insulin-dependent DM, } \\
\text { history of alcoholism }\end{array}$ & DM, pigmentation & $1206 \mathrm{C}>\mathrm{A} / \mathrm{wt}$ in TFR2 & $\begin{array}{l}\text { FPN-like iron } \\
\text { overload }\end{array}$ \\
\hline 10 & $67 / F$ & $\begin{array}{l}\text { Biochemical liver } \\
\text { damage }\end{array}$ & Glucose-intolerance & $\begin{array}{l}187 \mathrm{C}>\mathrm{G}(\mathrm{H} 63 \mathrm{D}) / \text { wt in } H F E \\
\text { and } 714 \mathrm{C}>\mathrm{G} / \mathrm{wt} \text { in TFR2 }\end{array}$ & $\begin{array}{l}\text { Intravenousiron } \\
\text { load }\end{array}$ \\
\hline 11 & $33 / F$ & Mild anemia & None & $\begin{array}{l}\text { No mutations in the } \\
\text { IOS genes }\end{array}$ & $\begin{array}{l}\text { Intravenousiron } \\
\text { load }\end{array}$ \\
\hline
\end{tabular}

aCP, aceruloplasminemia; DM, diabetes mellitus; F, female; FPN, ferroportin disease; $\mathrm{HH}$, hemochromatosis; IOS, iron overload syndromes; M, male. 
Ono Y. et al: Copper in hemosiderins

Table 2. Biochemical parameters of patients and the compound overload of iron and copper in their livers

\begin{tabular}{|c|c|c|c|c|c|c|c|c|}
\hline Patient & Diagnosis & $\begin{array}{l}\text { Ferritin } \\
(12-300 \\
\mathrm{ng} / \mathrm{mL})\end{array}$ & $\begin{array}{l}\text { TF-S } \\
(30-60 \%)\end{array}$ & $\begin{array}{l}\text { Hepcidin } \\
(10-20 \\
\mathrm{ng} / \mathrm{mL})\end{array}$ & $\begin{array}{l}\mathrm{Cu} \\
(60-120 \\
\mu g / d L)\end{array}$ & $\begin{array}{l}\text { CP } \\
(18-27 \\
m g / d L)\end{array}$ & $\begin{array}{l}\text { Liver histology } \\
\text { and iron deposits } \\
\text { in the liver }\end{array}$ & $\begin{array}{l}\text { Overload }^{* 1} \text { in } \\
\text { hepatocytes } \\
\text { [in RE cells] }\end{array}$ \\
\hline 1 & $\mathrm{aCP}$ & 961 & 22.0 & 2.7 & 2 & $\mathrm{BDL}$ & $\begin{array}{l}\text { Normal, selective } \\
\text { parenchymal }\end{array}$ & $\mathrm{Fe}(+2), \mathrm{Cu}(+)$ \\
\hline 2 & $\mathrm{aCP}$ & 952 & 11.6 & $\mathrm{BDL}$ & 9 & $\mathrm{BDL}$ & $\begin{array}{l}\text { Normal, selective } \\
\text { parenchymal }\end{array}$ & $\mathrm{Fe}(+2), \mathrm{Cu}(+)$ \\
\hline 3 & $\mathrm{HJV}-\mathrm{HH}$ & 4278 & 95.8 & - & 67 & 17 & $\begin{array}{l}\text { Cirrhosis, } \\
\text { parenchymal }\end{array}$ & $\mathrm{Fe}(+2), \mathrm{Cu}(+)$ \\
\hline 4 & $\mathrm{HJV}-\mathrm{HH}$ & 6115 & 94.8 & 0.3 & 117 & 35 & $\begin{array}{l}\text { Cirrhosis, } \\
\text { parenchymal }\end{array}$ & $\mathrm{Fe}(+3), \mathrm{Cu}(+/-)$ \\
\hline 5 & TFR2-HH & 1470 & 93.2 & 0.5 & 113 & 89.1 & $\begin{array}{l}\text { Fibrosis, } \\
\text { parenchymal }\end{array}$ & $\mathrm{Fe}(2+), \mathrm{Cu}(+)$ \\
\hline 6 & TFR2-HH & 10191 & 94.2 & 12.2 & 104 & 25.8 & $\begin{array}{l}\text { Cirrhosis, } \\
\text { parenchymal }\end{array}$ & $\mathrm{Fe}(+3), \mathrm{Cu}(+/-)$ \\
\hline 7 & TFR2-HH & 2485 & 94.5 & 0.7 & 113 & 41.1 & $\begin{array}{l}\text { Pre-Cirrhosis, } \\
\text { parenchymal }\end{array}$ & $\mathrm{Fe}(+2), \mathrm{Cu}(+)$ \\
\hline 8 & FPN & 7980 & 89.3 & 156.7 & 107 & 29 & $\begin{array}{l}\text { Fibrosis, compound } \\
\text { parenchymal and RE }\end{array}$ & $\begin{array}{l}\mathrm{Fe}(+3), \mathrm{Cu}(+) \\
{[\mathrm{Fe}(+3), \mathrm{Cu}(+)]}\end{array}$ \\
\hline 9 & $\begin{array}{l}\text { FPN-like } \\
\text { iron } \\
\text { overload }\end{array}$ & 6403 & 88.3 & 185.6 & 118 & 25.1 & $\begin{array}{l}\text { Fibrosis, compound } \\
\text { parenchymal and RE }\end{array}$ & $\begin{array}{l}\mathrm{Fe}(+2), \mathrm{Cu}(+/-) \\
{[\mathrm{Fe}(+3), \mathrm{Cu}(+)]}\end{array}$ \\
\hline 10 & $\begin{array}{l}2^{\text {nd }} \text { iron } \\
\text { overload }\end{array}$ & 7274 & 88.7 & 142.5 & 89 & 20.0 & $\begin{array}{l}\text { Cirrhosis, compound } \\
\text { parenchymal and RE }\end{array}$ & $\begin{array}{l}\mathrm{Fe}(+3), \mathrm{Cu}(+) \\
{[\mathrm{Fe}(+3), \mathrm{Cu}(+)]}\end{array}$ \\
\hline 11 & $\begin{array}{l}2^{\text {nd }} \text { iron } \\
\text { overload }\end{array}$ & 2076 & 91.1 & 172.5 & 134 & 32 & $\begin{array}{l}\text { Normal, selective } \\
\text { parenchymal }\end{array}$ & $\mathrm{Fe}(+2), \mathrm{Cu}(+)$ \\
\hline
\end{tabular}

aCP, aceruloplasminemia; $\mathrm{BDL}$, below the detection limit; CP, ceruloplasmin; FPN, ferroportin disease; RE, reticuloendothelial cell; TF-S, iron saturation to transferrin.

*1 Fe deposits were graded as Fe $(+3)$ when most dense bodies were heavily loaded, Fe $(+2)$ when moderately loaded, and Fe $(+1)$ when mildly loaded with iron expressed by Fe $\mathrm{K} \alpha$ peaks. Cu was expressed as $\mathrm{Cu}(+)$ when more than $10 \%$ of dense bodies were positive for $\mathrm{Cu} \mathrm{Ka}$ peaks, Cu (+/-) when between 2 and $10 \%$ dense bodies were positive and $\mathrm{Cu}(-)$ when more than 50 dense bodies (less than $2 \%$ ) were all negative.

Two-dimensional imaging revealed that most dense bodies in hepatocytes were composed of iron, phosphorous, and oxygen. These three elements were distributed similarly within dense body matrices, although phosphorous levels

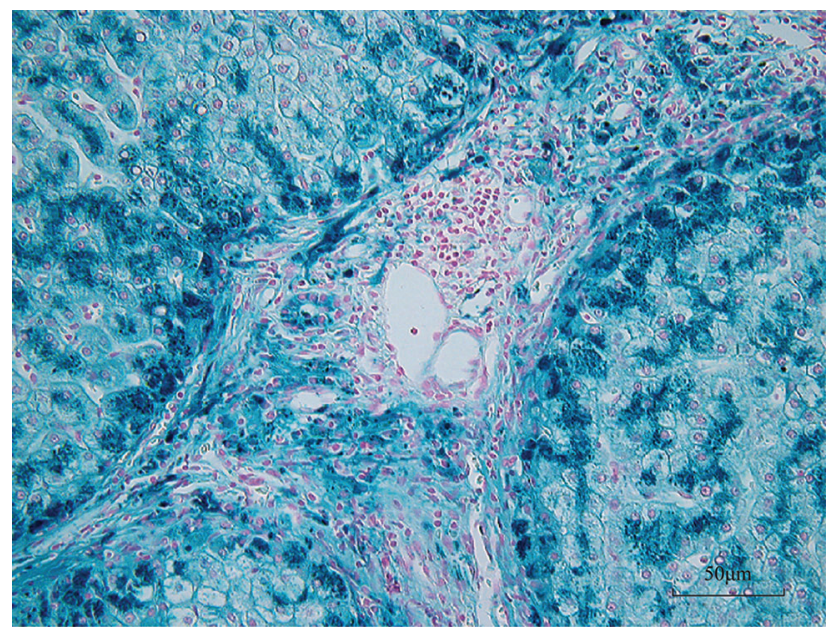

Fig. 1. Berlin blue iron stain for TFR2-hemochromatosis liver. Most parenchymal cells and some mesenchymal cells in fibrous bands, including bile ducts, were loaded with heavy iron grains, and Kupffer cells in degenerative nodules were minimally affected by iron loading. were slightly lower. The colocalization of copper with iron was confirmed in a limited number of iron-rich dense bodies, although copper levels were relatively low (Fig. 4). Copper commonly coexisted with sulfur. These five elements were

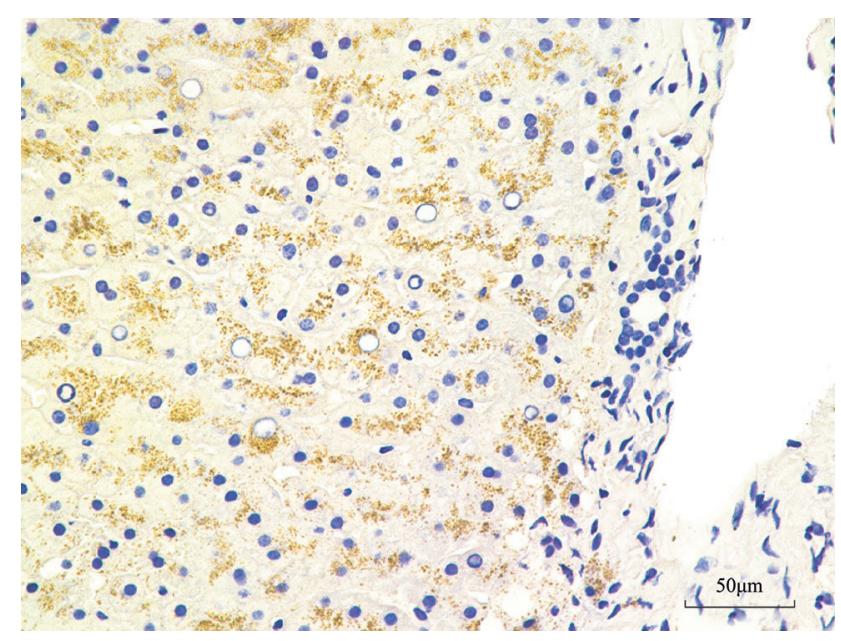

Fig. 2. Rhodanic acid copper stain for aceruloplasminemia liver Difficulties were encountered when evaluating copper deposits in hemosiderins because all iron-rich hemosiderins were originally bronze in color. Some hepatocyte nuclei were vacuolated and portal fibrosis was minimal. 
Ono Y. et al: Copper in hemosiderins

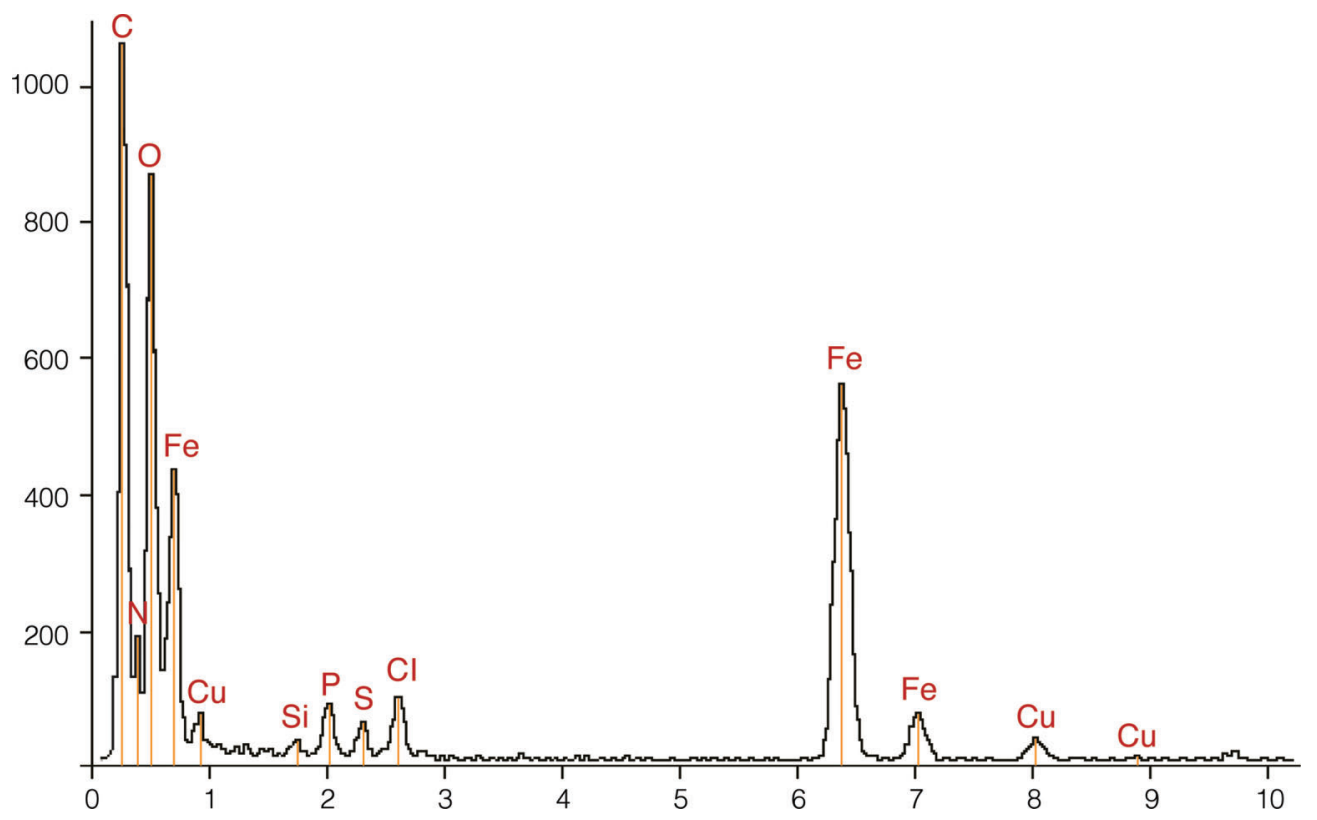

Fig. 3. An X-ray spectrum of hepatocellular dense body in ferroportin disease. Peaks in the $\mathrm{K} \alpha$ lines of C, N, O, Si, $\mathrm{P}, \mathrm{S}, \mathrm{Cl}, \mathrm{Fe}$, and Cu were observed in the spectrum. $\mathrm{C}, \mathrm{N}, \mathrm{O}, \mathrm{P}, \mathrm{S}, \mathrm{Fe}$, and $\mathrm{Cu}$ were intrinsic from the liver specimen, while those of Si and $\mathrm{Cl}$ were extrinsic from the epoxy resin. S commonly disappeared from dense bodies without copper deposits.
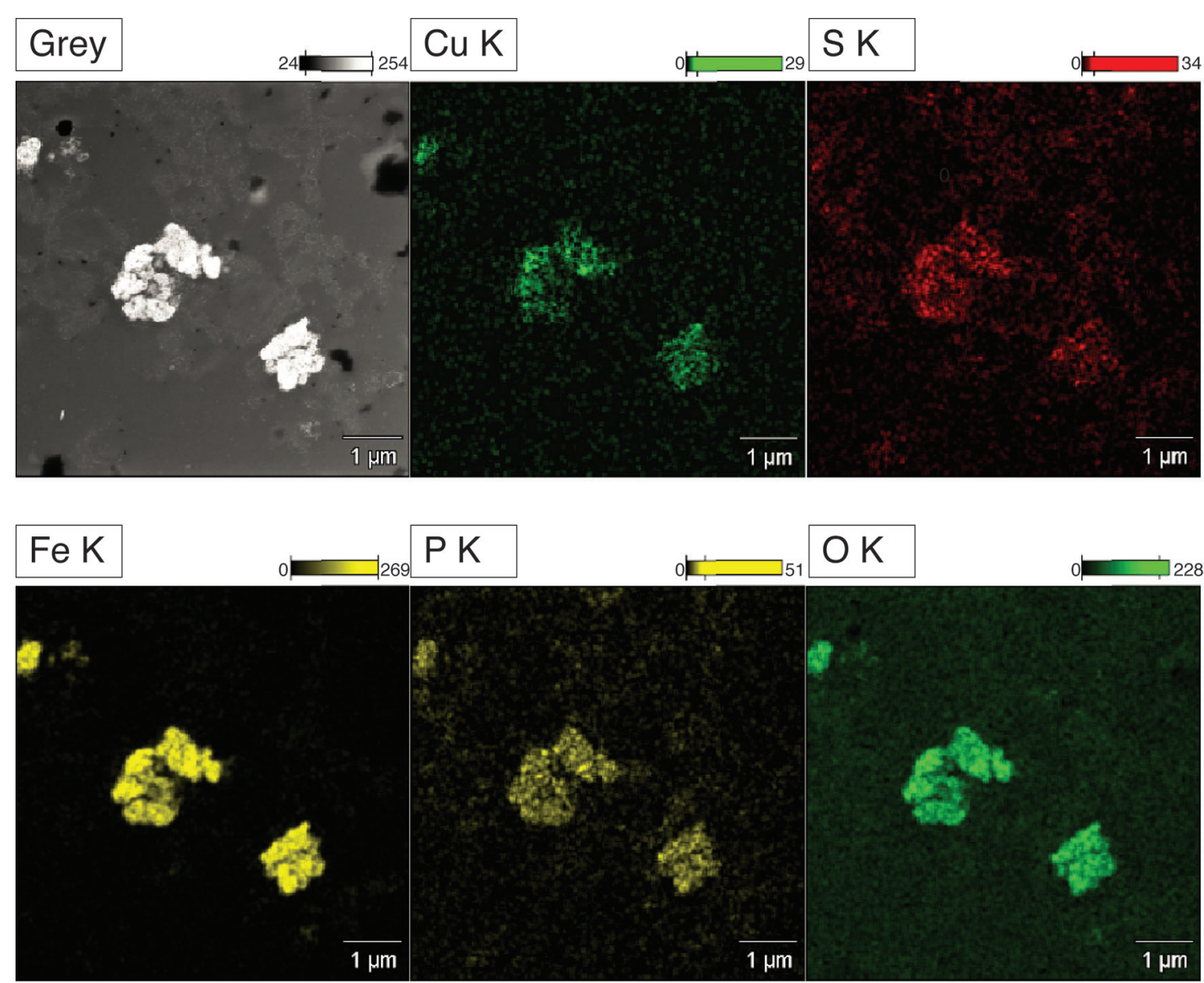

Fig. 4. Microanalysis of hepatocytes in ferroportin disease. The two-dimensional distribution of iron complex elements of oxygen (O K), phosphorus ( $\mathrm{K}$ ), and iron $(\mathrm{Fe} \mathrm{K})$ and cuproprotein elements of sulfur $(\mathrm{S} \mathrm{K})$ and copper $(\mathrm{Cu} \mathrm{K})$ were similar. Grey is a transmission electron microscopic image. $\mathrm{K}$ is the $\mathrm{K} \alpha$ line. 

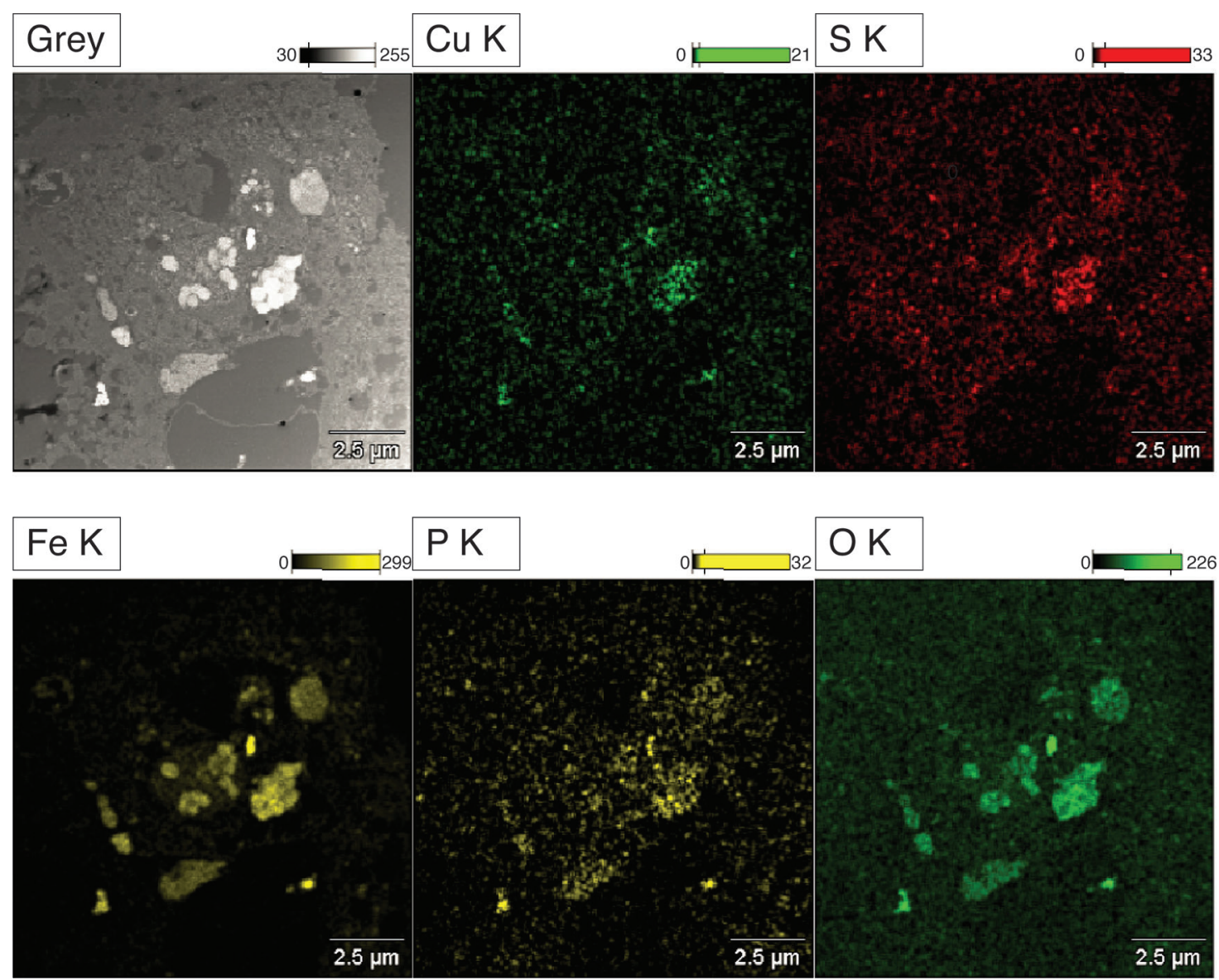

Fig. 5. Microanalysis of Kupffer cell in ferroportin disease. Various dense bodies aggregated in the cytoplasm of the Kupffer cell. However, the components of iron complexes of iron (Fe K), phosphorus ( $\mathrm{P} \mathrm{K})$, and oxygen $(\mathrm{O} K)$ and those of cuproproteins of copper (Cu K) and sulfur ( $\mathrm{S}$ K) were similarly distributed in these dense bodies. The densities of their matrices were dependent on the total contents of the two compounds. Grey is a transmission electron microscopic image. $\mathrm{K}$ is the $\mathrm{K} \alpha$ line.

evenly distributed in such dense bodies. Sulfur also disappeared in dense bodies without copper accumulation. No significant differences were observed in the colocalization of iron with copper between Kupffer cells and parenchymal cells. The density of metal-rich bodies in Kupffer cells was attributed to different iron and copper contents (Fig. 5).

The results of these MA are summarized in the right column of Table 2. Varying numbers of iron-rich dense bodies in hepatocytes were complicated by copper. The population of copper positive-dense bodies ranged from $10 \%$ and $30 \%$ in patients with $\mathrm{aCP}, \mathrm{FPN}$, and intravenous iron supplementation to less than $10 \%$ in patients with HJV- and TFR2-HH. Iron-rich granules in Kupffer cells also contained cuproproteins. The population of copper-positive dense bodies in Kupffer cells was similar to that in hepatocytes.

\section{Discussion}

We evaluated the interaction between iron and copper in the livers of 11 Japanese patients with iron overload syndromes. Two-dimensional imaging revealed the coexistence of a small amount of copper with a large amount of iron in the electron dense bodies of the livers of all patients with various iron overload syndromes. Iron coexisted with phosphorus and oxygen, suggesting the formation of phospho-oxidized iron complexes in hemosiderins, whereas copper coexisted with sulfur in iron-rich hemosiderins, suggesting that the copper component was derived from cuprothioneins. Iron complexes and cuproproteins were homogenously distributed within the matrices of iron-rich hemosiderins. These results suggested that heavy iron overload was responsible for the accumulation of cuproproteins in hemosiderins.

Most of the liver tissues used were first embedded in paraffin and re-embedded in epoxy resin for MA. The preparation of ultra-thin liver sections for MA is a multistep process that reduces the detection limits of iron complexes and copproproteins relative to that detectable from frozen sections of fresh tissues. ${ }^{8}$ The limited localization of the copper component visualized in iron-rich hemosiderins may not have been due to contamination during sampling but rather to the higher concentration of copper molecules in iron-rich dense bodies than in the nearby cytoplasm in patients with iron overload conditions.

The digenic background of $\mathrm{HH}$ and Wilson's disease ${ }^{17}$ was unlikely in our patients. Patients, except for those with $\mathrm{aCP}$, were unaffected by hypoceruloplasminemia, which suggested 
Wilson's disease. As far as five patients were concerned, the ATP7B analysis was negative for the mutations responsible for Wilson copper toxicosis. The coexistence of iron and copper was previously suggested to be associated with chronic cholestasis and end-stage liver diseases. ${ }^{18}$ However, the retention of copper in our patients could not be solely attributed to chronic cholestasis or cirrhosis. Two patients with $\mathrm{aCP}$ and one patient receiving intravenous iron supplementation did not exhibit portal fibrosis. Therefore, chronic cholestasis was also unlikely in these patients with an intact biliary system. Some, but not all copper may accumulate in hemosiderins due to a novel mechanism other than copper stasis.

A large amount of hepatic copper was previously detected in patients with aCP who had heavy iron overload in their livers with an intact biliary system. ${ }^{19,20}$ This copper component in hemosiderins was not detected by rhodanic acid stain for copper because it was difficult to differentiate copper-positive from copper-negative hemosiderins by histochemistry. This was mainly attributed to the difficulties associated with differentiating the strong brown color of the iron pigment from the faint red rhodanic acid stain for copper with light microscopy. Neither serum levels of copper nor CP reflected altered metabolism of copper in our patients with iron overload conditions.

Lysosomes physiologically store small amounts of the transition elements of iron and copper and recycle these elements between aged and renewed organelles. ${ }^{10,12}$ In addition to the large amount of stored iron, the recycling of both iron complexes and cuproproteins may be activated in patients with iron overload condition, because the redox state is known to be tightly regulated by cuproproteins, including multicopper oxidases and $\mathrm{Cu} / \mathrm{Zn}$ superoxide dismutase. ${ }^{6,7,14}$ Cuproproteins in hemosiderins may represent an aspect of the increased copper requirements needed to stabilize an activated redox state in iron overload conditions in addition to copper stasis in cirrhotic livers. During the recycling processes of trace elements, excess copper may be physiologically secreted into the bile, ${ }^{5}$ whereas iron, regardless of its amount, must be restored in lysosomal dense bodies of hepatocytes because of the lack of a secretory pathway for excess iron. ${ }^{2}$ This may be the mechanism responsible for the limited amount of copper observed in iron-rich hemosiderins.

The coexistence of iron-rich hemosiderins with cuproproteins is compatible with the biochemical analysis. An in vitro study previously demonstrated the coexistence of various transition elements including copper and iron in isolated hemosiderins. ${ }^{21}$ Copper levels were the second highest after those of iron in hemosiderins collected from an untreated patient with $\mathrm{HH}$.

The origin of cuproproteins in hemosiderins remains largely unknown. Lysosomal copper has been identified in the two pathological conditions, Wilson's disease and chronic cholestasis, in which the physiological secretion of copper into the bile is blocked. The coexistence of cuproproteins with iron-rich dense bodies strongly suggests a novel mechanism in which cuproproteins appear in lysosomes as an interface of enhanced copper metabolism in iron overload conditions.

All 11 patients in the present study were Japanese; none were Caucasians with HFE-HH. ${ }^{2}$ Therefore, the coexistence of cuproproteins with iron complexes in hemosiderins needs to be confirmed in a larger number of patients, especially in those with HFE-HH.

\section{Conclusions}

TEM-EDX provided morphological evidence that copper metabolism was widely altered under iron overload conditions.

\section{Acknowledgements}

We thank Drs. T. Sohda (Fukuoka University), T. Shibata (Ohgaki Municipal Hospital), and K. Tsuchida (Manda General Hospital) for providing the clinical data of patients.

\section{Conflict of interest}

None

\section{Author contributions}

Conception and design ( $\mathrm{YO}, \mathrm{MI}, \mathrm{KH}, \mathrm{YH}, \mathrm{HG}$ ), provision of study materials or patients (KK, NM, TY, MK, MW, HO, MT), collection and assembly of data $(\mathrm{SW}, \mathrm{HH})$, data analysis and interpretation ( $\mathrm{HM}, \mathrm{KY})$, manuscript writing and final approval of manuscript (all authors).

\section{References}

[1] Anderson GJ, Frazer DM. Hepatic iron metabolism. Semin Liver Dis 2005;25: 420-432. doi: 10.1055/s-2005-923314.

[2] Pietrangelo A. Hereditary hemochromatosis: pathogenesis, diagnosis, and treatment. Gastroenterology 2010;139:393-408.e1-e2. doi: 10.1053/j. gastro.2010.06.013.

[3] Hattori A, Miyajima H, Tomosugi N, Tatsumi $Y$, Hayashi H, Wakusawa S. Clinicopathological study of Japanese patients with genetic iron overload syndromes. Pathol Int 2012;62:612-618. doi: 10.1111/j.1440-1827.2012. 02848.x.

[4] Winter WE, Bazydlo LA, Harris NS. The molecular biology of human iron metabolism. Lab Med 2014;45:92-102.

[5] Gitlin JD. Wilson disease. Gastroenterology 2003;125:1868-1877. doi: 10. 1053/j.gastro.2003.05.010

[6] Vashchenko G, MacGillivray RT. Multi-copper oxidases and human iron metabolism. Nutrients 2013;27:2289-2313. doi: 10.3390/nu5072289.

[7] Zhao M, Matter K, Laissue JA, Zimmermann A. Copper/zinc and manganese superoxide dismutase immunoreactivity in hepatic iron overload diseases. Histol Histopathol 1995;10:925-935.

[8] Hanaichi T, Kidokoro R, Hayashi H, Sakamoto N. Electron probe X-ray analysis on human hepatocellular lysosomes with copper deposits: copper binding to a thiol-protein in lysosomes. Lab Invest 1984;51:592-597.

[9] Terman A, Kurz T. Lysosomal iron, iron chelation, and cell death. Antioxid Redox Signal 2013;10:888-898. doi: 10.1089/ars.2012.4885.

[10] Blaby-Haas CE, Merchant SS. Lysosome-related organelles as mediators of metal homeostasis. J Biol Chem 2014;289:28129-28136. doi: 10.1074/jbc. R114.592618.

[11] Wilson C, Venditti R, Rega LR, Colanzi A, D'Angelo G, DeMatteis MA. The Golgi apparatus: an organelle with multiple complex functions. Biochem J 2011; 433:1-9. doi: 10.1042/BJ20101058.

[12] Kurz T, Eaton JW, Brunk UT. The role of lysosomes in iron metabolism and recycling. Int J Biochem Cell Biol 2011;43:1686-1697. doi: 10.1016/j.biocel.2011.08.016.

[13] Filomeni G, DeZio D, Cecconi F. Oxidative stress and autophagy: the clash between damage and metabolic needs. Cell Death Differ 2015;22:377-388. doi: $10.1038 /$ cdd.2014.150.

[14] Meynard D, Babitt JL, Lin HY. The liver: conductor of systemic iron balance. Blood 2014;123:168-176. doi: 10.1182/blood-2013-06-427757.

[15] Hayashi H, Hattori A, Tatsumi Y, Hayashi K, Katano Y, Ueyama J, et al. Various copper and iron overload patterns in the livers of patients with Wilson disease and idiopathic copper toxicosis. Med Mol Morphol 2013;46:133-140. doi: 10.1007/s00795-013-0015-2.

[16] Murao N, Ishigai M, Yasuno $H$, Shimonaka $Y$, Aso $Y$. Simple and sensitive quantification of bioactive peptides in biological matrices using liquid 
chromatography/selected reaction monitoring mass spectrometry coupled with trichloroacetic acid clean-up. Rapid Commun Mass Spectrom 2007; 21:4033-4038. doi: 10.1002/rcm.3319.

[17] Walshe JM, Cox DW. Effect of treatment of Wilson's disease on natural history of haemochromatosis. Lancet 1998;352:112-113. doi:10.1016/S01406736(98)85017-4.

[18] Ishida M, Nakagawara G, Imamura Y, Fukuda M. Iron and copper deposition in chronic active hepatitis and liver cirrhosis; pathogenetic role in progressive liver cell damage. Eur J Histochem 1995;39:221-236.
[19] Miyajima $H$, Nishimura $Y$, Mizoguchi $K$, Sakamoto $M$, Shimizu $T$, Honda N. Familial apoceruloplasmin deficiency associated with blepharospasm and retinal degeneration. Neurology 1987;37:761-767.

[20] Morita H, Ikeda S, Yamamoto K, Morita S, Yoshida K, Nomoto S, et al. Hereditary ceruloplasmin deficiency with hemosiderosis: a clinicopathological study of a Japanese family. Ann Neurol 1995;37:646-656.

[21] Ward RJ, Ramsey MH, Dickson DP, Florence A, Crichton RR, Peters TJ, et al. Chemical and structural characterisation of iron cores of haemosiderins isolated from different sources. Eur J Biochem 1992;209:847-850. doi: $10.1111 /$ j.1432-1033.1992.tb17356.x. 